\title{
The investigation of actual evapotranspiration with the use of thermography
}

\author{
by P. Baranowski, W. Mazurek and R. T. Walczak
}

The Institute of Agrophysics Polish Academy of Sciences, 20-290 Lublin 27, Doświadczalna 4, Poland

\begin{abstract}
In the study actual evapotranspiration was calculated from the energy balance equation in which the radiation temperature of plant cover is a component of sensible heat flux expressing the transport of heat energy from evaporating surface to the atmosphere. High differences in the course of sensible and latent heat fluxes for the lysimeters with different soil moisture levels were noticed. Daily courses of potential evapotranspiration calculated with different methods were compared with actual evapotranspiration under comfort soil water conditions. The hourly values of actual evapotranspiration in lysimeters with comfortable water conditions better follow the evapotranspiration calculated according to the Penman-Monteith and Kimberly-Penman formulae.
\end{abstract}

\section{Introduction}

Radiation temperature of canopy is an important agroclimatic parameter which can be used for evaluation of evaporation from soil surface and transpiration from plants. These two kinds of evaporation are jointly called evapotranspiration. The possibility of quantitative determination of evapotranspiration rate for different scales is essential in the investigations of water balance. Thermal images of agricultural areas are available from airborne or satellite levels. However, their proper interpretation requires the knowledge of interactions between different soil and meteorological factors affecting the actual value of crop radiation temperature. This knowledge can be obtained on the base of ground level study enabling precise control of different parameters influencing radiation temperature measurement.

Crop temperature can be used for determination of actual evapotranspiration by combination of energy balance equation of the active surface with the equations of vertical transport of latent and sensible heat fluxes. The transpiration rate is mainly determined by availability of soil water in plant root zone and by meteorological parameters in the atmospheric boundary layer. Therefore, the accuracy of evapotranspiration evaluation depends on taking into account a considerable number of physical parameters characterising the soil-plant-atmosphere system and on the precision of their measurement. Infrared thermography technique is a very good tool for the investigations of quantitative relation between evapotranspiration rate and the set of agroclimatic factors. Such precise investigations should precede the use of cheaper instruments, like hand-held infrared thermometers, enabling only qualitative evaluation of evapotranspiration process.

The aim of this investigation was the quantitative evaluation of hourly and daily values of actual and potential evapotranspiration of grass cover, under different soil moisture and meteorological conditions, on the base of thermographic measurements.

\section{Radiation temperature of the active surface in the equations of mass and energy transport in the soil-plant-atmosphere system}

The energy balance equation describes the process of energy exchange at the evaporating surface (e.g. crop surface). The most frequently used form of this equation is as follows:

$$
L \cdot E+H+R_{n}+G=0
$$

where: $L \cdot E$ - the latent heat flux $\left[\mathrm{W} \cdot \mathrm{m}^{-2}\right]$ (energetic equivalent of the evapotranspiration flux); $\mathrm{L}$ - the latent heat of vaporisation of water per unit mass $\left(\mathrm{L}=2,45 \cdot 10^{6} \mathrm{~J} \cdot \mathrm{kg}^{-1}\right) ; \mathrm{E}$ - 


\section{http://dx.doi.org/10.21611/qirt.1998.043}

evapotranspiration flux $\left[\mathrm{kg} \cdot \mathrm{m}^{-2} \cdot \mathrm{s}^{-1}\right] ; H$-the sensible heat flux $\left[\mathrm{W} \cdot \mathrm{m}^{-2}\right] ; \mathrm{R}_{n}$-the net radiation flux $\left[\mathrm{W} \cdot \mathrm{m}^{-2}\right] ; G$ - the heat flux into the soil $\left[\mathrm{W} \cdot \mathrm{m}^{-2}\right]$. In this equation fluxes towards the crop surface are considered positive and the fluxes out of the surface are considered negative value.

Heat and energy transport in soil-plant-atmosphere system can be described using resistance model analogue to an electric circuit. The transport equations for sensible heat $H$ and latent heat $L \cdot E$ in this case can be expressed as:

$$
\begin{gathered}
H=\rho \cdot c_{p} \frac{T_{c}-T_{a}}{r_{a h}} \\
L \cdot E=\frac{\rho \cdot c_{p}}{\gamma} \frac{e_{c}^{*}-e_{a}}{r_{a v}+r_{s}}
\end{gathered}
$$

where: $T_{c}$ - crop surface temperature $[\mathrm{K}] ; \mathrm{T}_{\mathrm{a}}$ - air temperature $[\mathrm{K}]$ measured at reference height $z_{a} ; e_{c}{ }^{*}$ - saturated vapour pressure $[\mathrm{Pa}]$ at the apparent crop temperature $T_{c} ; \quad e_{a} \quad-$ water vapour pressure of the air [Pa] measured at reference level $z_{a} ; r_{a h}, r_{a v}$ - diffusion resistance respectively for transport of heat and water vapour $\left[s^{\cdot} \mathrm{m}^{-1}\right] ; r_{s}$ - stomatal resistance of the crop $\left[\mathrm{s} \cdot \mathrm{m}^{-1}\right] ; \mathrm{p}$ - density of air $\left[\mathrm{kg} \cdot \mathrm{m}^{-3}\right] ; \gamma$ - psychrometric constant; $\mathrm{c}_{\mathrm{p}}$ - air specific heat $\left[\mathrm{J} \cdot \mathrm{kg}^{-1} \cdot \mathrm{K}^{-1}\right]$.

Aerodynamic resistance for heat transport $r_{\text {ah }}$ is a function of wind velocity, stability of the atmosphere over the plant cover and roughness of the surface. As a good approximation it can be assumed that $r_{a h}=r_{a v}=r_{a}$ (turbulent diffusion resistance for heat and water vapour transport). Combining equations (1), (2) and (3), the relation between actual value of radiation temperature of evaporating crop surface and agrometeorological parameters in the atmospheric boundary layer and soil

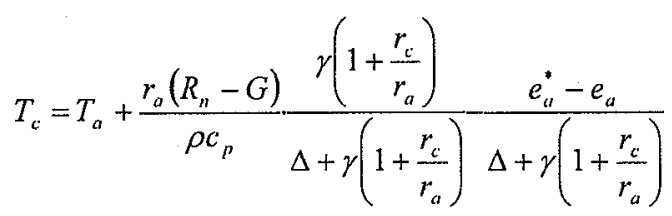

From this equation, it results that the difference between crop surface temperature and air temperature is linearly dependent on vapour pressure deficit in the air VPD $\left(e_{a}^{*}-e_{a}\right)$. This relation was used by Jackson et al. [3]. They created the crop water stress index (CWSI). This index is based on the relation of the actual evapotranspiration to potential evapotranspiration and is expressed as:

$$
C W S I=1-\frac{E_{a t}}{E_{p}}=\frac{\gamma\left(1+\frac{r_{c}}{r_{a}}\right)-\gamma\left(1+\frac{r_{c p}}{r_{a}}\right)}{\Delta+\gamma\left(1+\frac{r_{c}}{r_{a}}\right)}
$$

where: $E_{a}$ - actual evapotranspiration flux $\left[\mathrm{kg} \cdot \mathrm{m}^{-2} \cdot \mathrm{s}^{-1}\right]$;, $E_{p}$ - potential evapotranspiration flux $\left[\mathrm{kg} \cdot \mathrm{m}^{-2} \cdot \mathrm{s}^{-1}\right]_{i}, r_{\mathrm{cp}}$ - the canopy resistance at potential evapotranspiration $\left[\mathrm{s} \cdot \mathrm{m}^{-1}\right]$, the other symbols as in previous equations.

\section{Methods of actual and potential evapotranspiration estimation}

For calculation of hourly and daily values of actual evapotranspiration the heat balance method was used in which the latent heat flux is treated as an unknown in eq. 1 . Sensible heat flux was calculated from eq. 2 on the base crop surface radiation temperature measurement and the other components $\left(R_{n}\right.$ and $\left.G\right)$ were determined on the base of 
standard meteorological measurements [2]. On the base of radiation temperature differences in lysimeters and air temperature, the stability conditions in the boundary layer of atmosphere were determined. Turbulent diffusion resistance $r_{a}$ was calculated using equations of semiempirical theory of turbulence $[5,4]$. Daily values of actual evapotranspiration were compared with weighed daily losses of water from lysimeters.

Potential evapotranspiration was calculated using algorithms and procedures described in ASCE Manual No. 70. Hourly values of potential evapotranspiration were calculated using the following methods:

- Penman-Monteith with aerodynamic resistance (Allen et al., 1989);

- Kimberly-Penman (Wright, 1987);

- Penman 1963.

Besides these methods, for calculation of daily reference evapotranspiration values the following methods were used:

- FAO - 24 Penman (Doorenbos, Pruitt, 1975, 1977);

- Hargreaves temperature method - 1985;

- FAO - 24 radiation method (Doorenbos, Pruitt, 1975, 1977).

The hourly and daily actual evapotranspiration values from lysimeters with comfort water conditions were compared with potential evapotranspiration values obtained using different methods. Eq. (5) was used for calculation of CWSI.

\section{Experiment description}

The experiments were performed in lysimetric station of the Institute for Land Reclamation and Grassland Farming in Sosnowica. The object of the study was natural grass cover growing in lysimeters of the area $1700 \mathrm{~cm}^{2}$ and height $120 \mathrm{~cm}$. (Lysimeters with different ground water levels of sandy and peat soil). In the initial stage of the experiments an optimal water level of $60 \mathrm{~cm}$ was kept in all the lysimeters. Soil water content in lysimeters was differentiated. The pairs of lysimeters were created and in each pair there was one lysimeter with gravitational water completely carried away and the other one with soil water level representing the comfort water conditions for plants.

Thermal images of plant cover in lysimeters were taken with AGEMA 880 LWB. One minute sequences were taken every hour during daily hours and every two hours at night. The measurements of radiation temperature of each pair of lysimeters were done' from the distance of $4,3 \mathrm{~m}$ and height of $2,2 \mathrm{~m}$ with the angle $60^{\circ}$ between optical axis of the camera and the perpendicular. The whole day registration of meteorological data was performed with the use of automatic data acquisition system elaborated in IA PAS Lublin. The subsystem referring to the soil was composed of TDR (Time Domain Reflectometry) water content measuring device and thermoelectric sensors of soil temperature. The subsystem referring to the atmosphere was composed of thermoelectric sensors of air temperature, anemometers, psychrometers and sensors for direct and reflected short and long wave solar radiation. Water potential in plants was measured with Wescor device using dew point method.

\section{Results and discussion}

The experiments were conducted during 3 years in July and August. About 800 averaged images were obtained from the registered one-minute sequences. For each image the areas comprising plants in lysimeters were selected (parts of each area representing not plant cover were chopped) and the basic statistics of radiation temperature was performed.

The analysis of mean values of plant cover radiation temperature in lysimeters with comfort and stress soil water conditions showed that, for the days with high radiation and low air humidity, the differences of radiation temperature reached several degrees. For these conditions radiation temperature of plant cover in stressed lysimeters is higher than air temperature. Fig. 1 shows crop temperature data coming from day and night measurements under different meteorological conditions. Only for air temperature higher than $20^{\circ} \mathrm{C}$ the 
differences of crop temperatures occur between plants growing under extremely different soil water conditions.

The daily courses of heat balance components of a chosen pair of lysimeters is presented in Fig. 2. High differences in the course of sensible heat flux and latent heat flux were noticed between lysimeters with different soil water conditions.

The comparison of daily courses of potential evapotranspiration calculated with different methods and actual evapotranspiration presented in Fig. 3 allows to state that the hourly values of actual evapotranspiration in the lysimeters with comfortable water conditions follow best the evapotranspiration calculated according to the Penman-Monteith and KimberlyPenman formulae whereas under the water stress conditions its magnitudes are remarkably lower.

Accarding to eq. 4, the upper limit of crop-air temperature difference was found representing the complete restrain of evapotranspiration $\left(r_{c} \rightarrow \infty\right)$ and the lower limit which corresponds to the case of wet plants acting as free water surface $\left(r_{c}=0\right)$ (Fig. 4). The regression line for well watered plants is close to the lower limit line and the regression line for stressed plants is close to the upper limit. Upper and lower limits in Fig. 4 were calculated for net radiation higher than $500 \mathrm{~W} / \mathrm{m}^{2}$, turbulent aerodynamic resistance $90 \mathrm{~s} / \mathrm{m}$ for stressed plant cover and $68 \mathrm{~s} / \mathrm{m}$ for plants in comfortable water conditions and air temperature equal to $30^{\circ} \mathrm{C}$.

Hourly values of CWSI and crop temperature are presented in Fig. 5 for plant cover in lysimeters of one pair. CWSI was calculated from equation 5 . Potential evapotranspiration was calculated from Penman-Monteith formula and actual evapotranspiration using heat balance method. During daily hours, significant differences in crop cover temperature correspond with high differences in evapotranspiration rates and at the same time CWSI values.

Evapotranspiration intensity is mainly determined by availability of soil water for plants. High differences of water potential exist in soil-plant-atmosphere system. Under high atmospheric evaporative demand (high water pressure deficit), the differences of soil water potential lead to considerable differences of plant water potential and evapotranspiration rate. In Fig. 6 high differences of plant water potential are observed for succeeding days between the lysimeters of one pair. Simultaneously, high differences of CWSI values are noticed.

Considering daily values of potential and actual evapotranspiration the meaningful differences were noticed between lysimeters with stress and comfort conditions and between lysimeters with organic and mineral soils.

Infrared thermography is a good tool in the studies of plant water stress and evapotranspiration. It enables automatic averaging of the thermal characteristics of a great number of individual plants from a large area and at the same time, as opposed to the infrared thermometers, it gives the possibility of selecting in the image and eliminating thermal sygnals coming from disturbing objects (eg. shown through soil).

Plant cover temperature in connection with standard meteorological data when incorporated into the heat balance equation makes it possible to determine hourly and daily values of actual evapotranspiration. The combination of actual and potential evapotranspiration values leads to creation of the index of plant water stress CWSI, which is sensitive to the atmospheric-evaporative demand and plant water potential.

Obtained results confirm the need of the application of thermography in the studies of evapotranspiration.

\section{REFERENCES}

[1] ALLEN (R. G.), JENSEN (M. E.), WRIGHT (J. L.), BURMAN (R. D.) - Operational estimates of reference evapotranspiration. Agronomy Journal, 81:650-662, 1989.

[2] BARANOWSKI (P.), MAZUREK (W.), WALCZAK (R. T.) - Weryfikacja modeli wyliczania ewapotranspiracji $w$ badaniach lizymetrycznych z zastosowaniem pomiaru temperatury 
radiacyjnej. Materiały III Ogólnopolskiej Konferencji Termografii i Termometrii w Podczerwieni, Warszawa 27-29 November 1996, pages. 219-224.

[3] JACKSON (R. D.), IDSO (S. B.), REGINATO (R. J.), PINTER (P. J.) - Canopy temperature as a crop water stress indicator. Water Resour. Res., Vol.17, No.4: 1133$1138,1981$.

[4] JACKSON (R. D.), MORAN (M. S.), GAY (L. W.), RAYMOND (L. H.) - Evaluating evaporation from field crops using airborne radiometry and ground-based meteorological data. Irrig. Sci., 8:81-90, 1987.

[5] SOER (G. J. R.) - The TERGRA model - a mathematical model for the simulation of the daily behaviour of crop surface temperature and actual evapotranspiration. NIWARS publ. 46, Delft, 1977.

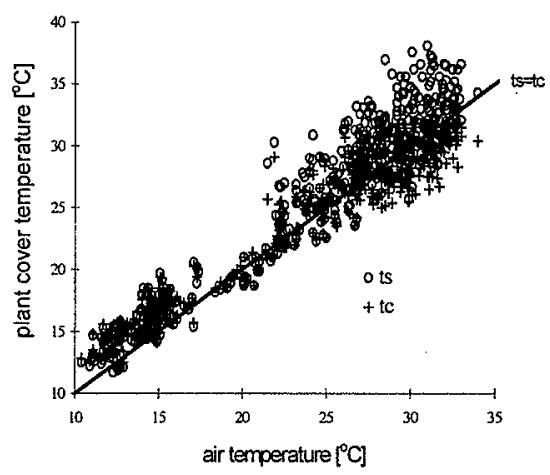

Fig. 1. Radiation temperature of grass cover in stress $t_{s}$ and nonstress $t_{c}$ soil water conditions versus air temperature

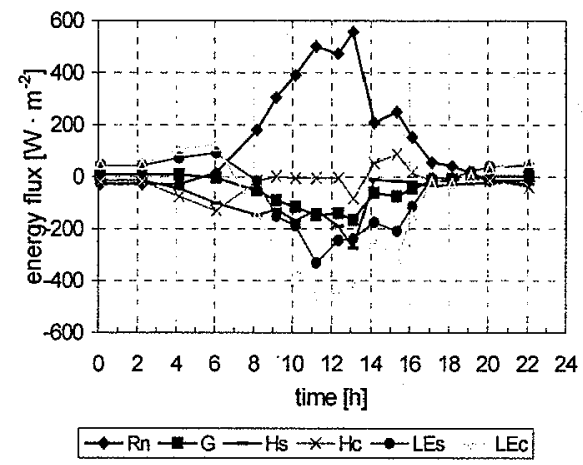

Fig. 2. Example of daily courses of heat balance components: $\mathbf{R}_{\mathbf{n}}$ - net radiation, $G$ - heat flux in the soil, $H_{s}$ and $H_{c}$ - sensible heat fluxes of stressed and non-stressed lysimeters, LE $_{s}$ and $L E_{c}$ - latent heat fluxes

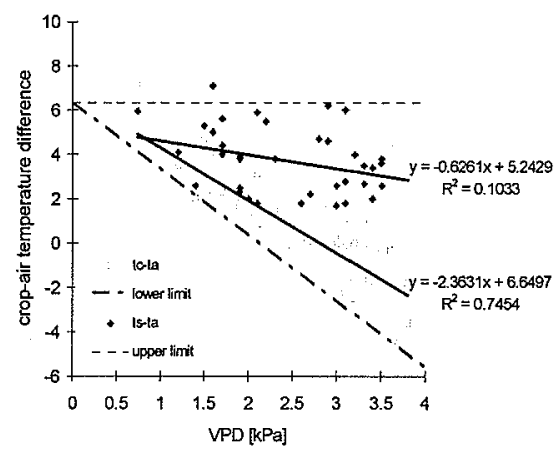

Fig. 4. The relation between crop-air temperature difference for stressed ts-ta and non-stressed tc-ta plants and vapour pressure deficit 
http://dx.doi.org/10.21611/qirt.1998.043

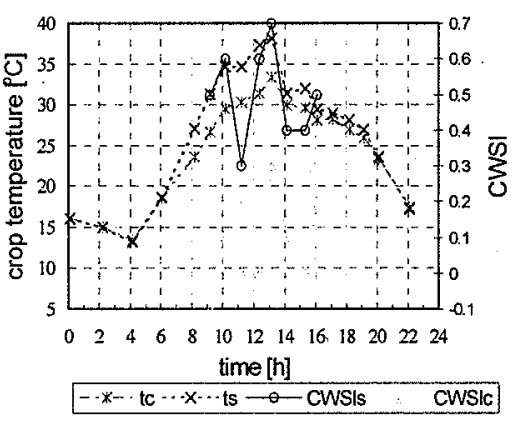

Fig. 5. Daily changes of CWSI for water stressed and non-stressed plants against a background of crop temperature courses

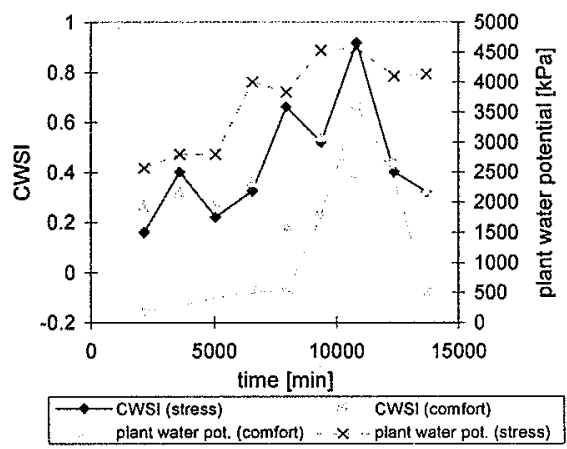

Fig. 6. Changes of daily values of plant water potential and resulting changes of CWSI for stressed and non-stressed plants 